\title{
ANALISA BATAS DAERAH ALIRAN SUNGAI DARI DATA ASTER GDEM TERHADAP DATA BPDAS (STUDI KASUS : SUB DAS BUNGBUNTU DAS TAROKAM)
}

\author{
Yogyrema Setyanto Putra, Muhammad Taufik \\ Program Studi Teknik Geomatika, Fakultas Teknik Sipil dan Perencanaan \\ Institut Teknologi Sepuluh Nopember (ITS) Surabaya \\ Jl. Arief Rahman Hakim, Surabaya 60111 Indonesia \\ e-mail: zoirema@yahoo.com
}

\begin{abstract}
Abstrak
Pemetaan batas daerah aliran sungai (DAS) merupakan salah satu parameter utama yang digunakan sebagai batasan penentuan kondisi tutupan lahan dan geomorfologi pada DAS. Ketersediaan data Digital Elevation Model (DEM), dapat dimanfaatkan sebagai pengelolaan DAS dalam bentuk pemetaan batas DAS serta mendapatkan kondisi geomorfologi DAS. Sayangnya keberagaman produk data DEM sering menimbulkan pertanyaan bagi pengguna tentang produk data DEM manakah yang sebaiknya digunakan dalam penelitiannya.

Penelitian ini bertujuan untuk mendapatkan hasil perbandingan dari batas DAS yang diolah yaitu menggunakan data ASTERGlobal Digital Elevation Model (GDEM) terhadap data Badan Pengelolaan Daerah Aliran Sungai (BPDAS). Metode yang dilakukan dalam penelitian ini mencakup pra pengolahan, pengolahan, dan kartografis. Pada pra pengolahan citra proses yang dilakukan antara lain pemotongan citra $D E M$, koreksi geometrik, ekstraksi garis kontur Peta RBI ke DEM, pengkoreksian jaringan sungai BPDAS terhadap Peta RBI. Pada tahap pengolahan dilakukan analisa hidrologi permukaan pada data DEM untuk mendapat batas DAS. Pada tahap akhir dilakukan kartografi untuk pembuatan peta batas dimana data batas ditampalkan.
\end{abstract}

Berdasarkan hasil penelitian, secara kuantitatif nilai morfometri hasil pengolahan ASTER GDEM menunjukkan nilai yang berbeda dengan data BPDAS, tetapi masih dalam rentang kelas benuk DAS yang sama.

Kata Kunci : ASTER GDEM, Daerah Aliran Sungai (DAS), DEM SRTM, Digital Elevation Model (DEM).

\section{PENDAHULUAN}

\section{Latar Belakang}

Pemetaan daerah aliran sungai (DAS) merupakan salah satu bentuk upaya Badan Pengelolaan Daerah Aliran Sungai (BPDAS) dalam pengelolaan DAS.

Pemetaan DAS tersebut mencakup pemetaan batas, kondisi lingkungan, tutupan lahan, dan morfometri DAS. Berbagai penelitian telah dilakukan untuk membandingkan ketelitian vertikal data DEM. Beberapa penelitian mengungkapkan ketelitian ASTER GDEM lebih rendah dibanding $D E M$ lainnya. Tetapi salah satu penelitian dalam pengaplikasian data DEM dalam menentukan batas DAS, menyatakan bahwa ASTER GDEM lebih baik daripada DEM lainnya. Dengan penelitian ini, diharapkan dapat memberikan hasil sejauh mana ASTER GDEM dapat menghasilkan batas DAS yang mendekati nilai kelas batas yang ditentukan oleh BPDAS.

\section{Batasan Masalah}

1. Batasan studi pada penelitian ini ialah pada Sub DAS Bungbuntu DAS Tarokam, Kabupaten Pamekasan, Jawa Timur.

2. Penelitian ini dilakukan dengan menggunakan data BPDAS, Peta RBI, dan ASTER GDEM.

3. Penelitian yang dilakukan ialah tentang pemetaan batas DAS.

\section{Tujuan Penelitian}

1. Menghasilkan batas DAS dari pengolahan data ASTER GDEM.

2. Membandingkan hasil pengolahan batas DAS hasil pengolahan data ASTER GDEM terhadap data DAS BPDAS.

3. Menghasilkan output berupa Peta Batas Sub DAS Bungbuntu DAS Tarokam.

\section{METODOLOGI PENELITIAN}

Penelitian ini mengambil studi kasus di Sub DAS Bungbuntu DAS Tarokam. Secara geografis, Sub DAS Bungbuntu terletak di $7,027^{\circ}-7,15^{\circ}$ LS dan 
$113,438^{\circ}$ - $113,529^{\circ}$ BT, secara administratif terletak di dalam Kabupaten Pamekasan, Jawa Timur.

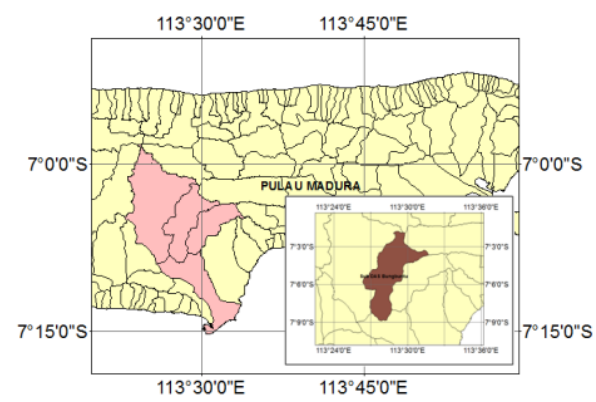

Gambar 1. Lokasi Penelitian Sub DAS Bungbuntu DAS Tarokam

\section{Bahan dan Peralatan}

1. Bahan

Data primer merupakan data yang diolah pada penelitian ini yang diperoleh dengan cara mengunduh data secara gratis yaitu data ASTER GDEM V2. Untuk data sekunder dari instansi BPDAS, meliputi data batas, dan morfometri Sub DAS Bungbuntu DAS Tarokam.

\section{Peralatan}

Peralatan yang digunakan dalam penelitian ini meliputi perangkat keras (Hardware) yaitu Personal Computer dan perangkat lunak (Software) untuk mengolah data spasial.

\section{Metode Pengolahan Data}

Metode pengolahan yang dilakukan adalah sebagai berikut:

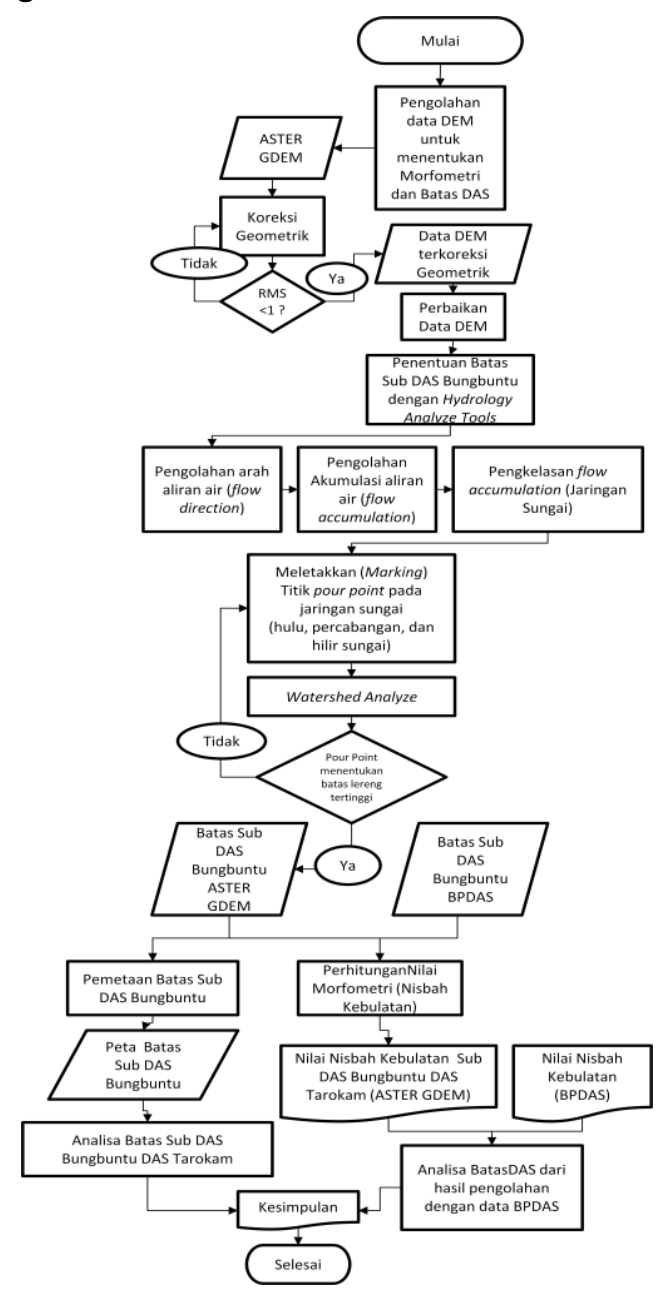

Gambar 2. Metode pengolahan Data

1. Koreksi Geometrik

Koreksi geometrik dilakukan pada dua data yang diproduksi oleh instansi yang berbeda, yaitu antara produk Indonesia berupa Peta RBI dan produk USGS NASA berupa data DEM dan citra satelit Landsat 8. Yang dijadikan sebagai dasar koreksi geometrik ialah data vektor jaringan sungai RBI. Proses koreksi geometrik dilakukan dengan mengambil kenampakan alam sungai berdasarkan citra Landsat 8 true colour composite yang ditampalkan ke Peta RBI. 8 titik yang merepresentasikan bentuk sungai diambil sebagai koreksi geometrik dari Sub DAS Bungbuntu. 


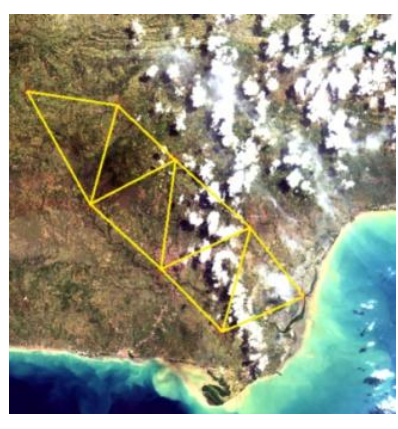

Gambar 3. Jaring pada koreksi geometrik.

2. Pengolahan Hidrologi Permukaan untuk menentukan aspek pembuatan DAS

Data DEM SRTM dan ASTER GDEM digunakan sebagai data utama yang diolah untuk mendapatkan batas SubDAS Bungbuntu DAS Tarokam. Pada awalnya dilakukan perbaikan pada data DEM untuk mengisi kekosongan data yang terdapat pada tiap piksel DEM. Data DEM yang telah diperbaiki selanjutnya diolah dalam perangkat lunak pengolahan hidrologi permukaan. Proses tersebut akan menentukan mulai dari aliran air, akumulasi aliran, jaringan sungai, dan orde sungainya. Sayangnya di dalam penentuan jaringan sungai oleh data DEM SRTM dan ASTER GDEM tidak sesuai dengan jaringan sungai pada peta RBI. Sehingga perhitungan morfometri jaringan sungai dari data DEM SRTM dan ASTER GDEM diganti dengan data vektor jaringan sungai terkoreksi milik BPDAS untuk mendapatkan nilai tingkat percabangan dalam morfometri Sub DAS Bungbuntu DAS Tarokam.

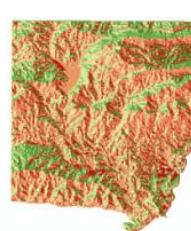

(A)

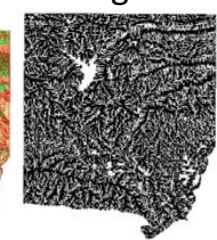

(B)

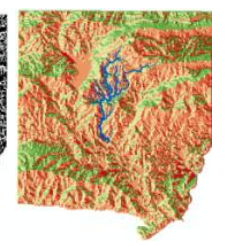

(C)
Gambar 4. (A) Arah aliran; (B) Akumulasi aliran; (C) Jaringan sungai

3. Pembuatan Batas DAS

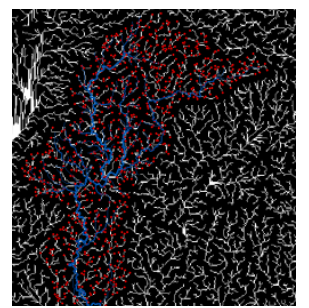

Gambar 5. Flow accumulation dan pour point dalam menentukan batas DAS data ASTER GDEM
Pembuatan batas DAS memperhatikan parameter akumulasi aliran dan jumlah Pour Point sebagai penanda adanya aktifitas aliran air yang terjadi di dalam DAS. Pour point tersebut diletakkan di sepanjang percabangan pada akumulasi aliran hingga hilir atau pertemuan antar SubDAS yang masih bersambungan.

\section{HASIL dan PEMBAHASAN}

1. Perbandingan Luasan, Keliling, dan nisbah kebulatan Data Batas DAS ASTER GDEM terhadap data BPDAS

Perhitungan tiap data DEM menghasilkan sebuah nilai luas, keliling dan nisbah kebulatan pada tabel berikut:

Tabel 1. Perbandingan nilai morfometri dari data DEM terhadap BPDAS

\begin{tabular}{cccc}
\hline \multicolumn{4}{c}{ terhadap BPDAS } \\
\hline $\begin{array}{c}\text { Parameter } \\
\text { Morfometri }\end{array}$ & $\begin{array}{c}\text { Nilai } \\
\text { ASTER } \\
\text { GDEM }\end{array}$ & BPDAS & Satuan \\
\hline \hline Luas DAS & 48,205 & 48,138 & $\mathrm{Km}^{2}$ \\
$\begin{array}{c}\text { Keliling } \\
\text { Nisbah } \\
\text { Kebulatan } \\
\text { (Rc) }\end{array}$ & 45,099 & 41,412 & $\mathrm{Km}$ \\
\hline \hline
\end{tabular}

Berdasarkan hasil perhitungan, luasan ASTER GDEM menyerupai nilai luasan dari BPDAS, dari nisbah kebulatan masih memiliki selisih 0,55. Bentuk DAS yang di hasilkan oleh ASTER GDEM masih belum menyerupai BPDAS, dimana ada beberapa daerah yang masuk kawasan Sub DAS dan ada kawasan yang hilang. Dapat terlihat pada Desa tebul Barat (bagian utara Sub DAS) tidak masuk dalam Sub DAS Bungbuntu DAS Tarokam, tetapi ASTER GDEM memiliki kesamaan menunjukkan batas Sub DAS yang berbentuk memanjang.

2. Peta Perbandingan Batas Sub DAS Bungbuntu DAS Tarokam dari Data DEM SRTM dan ASTER GDEM Terhadap Data Batas Sub DAS BPDAS

Sasil pengolahan batas Sub DAS antara ASTER GDEM terhadap batas Sub DAS Bungbuntu DAS Tarokam keluaran BPDAS. 


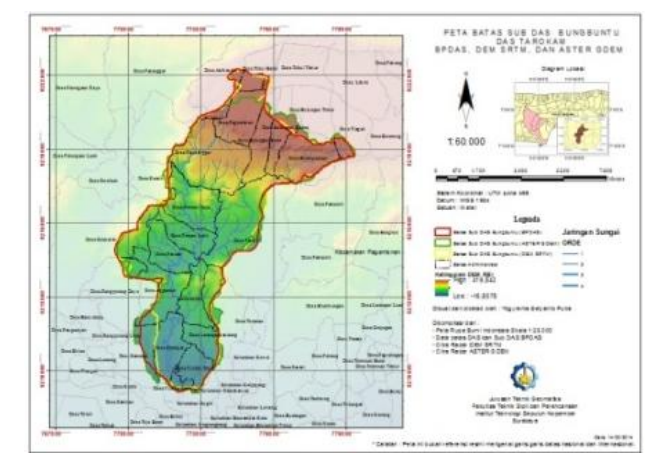

Gambar 6. Peta Batas Sub DAS Bungbuntu DAS Tarokam dari data DEM SRTM (kuning) dan ASTER GDEM (hijau), terhadap data batas DAS BPDAS (Merah)

\section{PEMBAHASAN}

Analisa Proses Pengolahan Penentuan Batas DAS Menurut Hery T.P. (2013), pour point yang merupakan faktor penting dalam menentukan DAS yang diletakkan pada titik percabangan sungai .( Rahayu, S., Widodo, R.H., Noordwijk, M.V., Suryadi, I., \& Verbist, B., 200)

Dari hasil klasifikasi sungai, dengan metode yang diterapkan, yaitu memberikan pour point pada percabangan sungai tidak mendapatkan hasil yang maksimal (menyerupai batas DAS BPDAS). Hal ini dikarenakan tergantung pada proses pengklasifikasian nilai flow accumulation, dimana semakin kecil nilai kelas flow accumulation semakin teliti dalam pembuatan batas DAS-nya karena titik pour point yang digunakan akan semakin banyak, begitu juga sebaliknya. Tetapi, dalam mengkelaskan nilai tersebut juga tidak boleh terlalu kecil, karena akan menyebabkan kebingungan dalam menentukan batas DAS yang ada. Karena semakin kecil nilai flow accumulation, semakin rapat garis yang dibentuk antar DAS-nya, begitu pula sebaliknya.

\section{Analisa Spasial Perbandingan Batas Sub DAS Bungbuntu DAS Tarokam}

Titik tinggi pada tiap piksel data DEM merupakan penentu gradien / kemiringan antar titiknya. Dalam menentukan batas DAS, titik titik tinggi ini menjadi penentu arah aliran air. Titik titik lereng tertinggi tersebut akan membentuk sebuah garis yang menjadi batas yang memisahkan arah aliran air tersebut. Garis yang membentuk poligon tersebutlah yang akan menjadi suatu batas pada daerah aliran sungai tersebut.

Pergeseran yang terjadi pada penentuan batas DAS dapat terjadi dikarenakan adanya pengaruh ketelitian tinggi pada DEM tersebut. Seperti halnya telah diketahui bahwa ketelitian tinggi dari data ASTER GDEM masih lebih rendah jika dibandingkan dengan ketelitian tinggi data DEM lainnya. Pengaruh tutupan lahan pada ketelitian tinggi data DEM akan sangat mempengaruhi dalam penentuan batas DAS terutama pada daerah yang landai.

\section{PENUTUP}

\section{Kesimpulan}

1. Batas DAS hasil ASTER GDEM kurang mampu merepresentasikan batas DAS sesuai dengan batas DAS milik BPDAS. Ini dapat dikarenakan adanya pengaruh ketelitian tinggi pada DEM tersebut. Seperti halnya telah diketahui bahwa ketelitian tinggi dari data ASTER GDEM masih lebih rendah jika dibandingkan dengan ketelitian tinggi data DEM lainnya. Pengaruh tutupan lahan pada ketelitian tinggi data DEM akan sangat mempengaruhi dalam penentuan batas DAS terutama pada daerah yang landai sehingga data DEM kesulitan dalam menentukan batas DAS. Ini mendukung penelitian sebelumnya yaitu penentuan batas DAS lebih sulit dilakukan pada daerah yang landai.

2. Secara kuantitatif, perbandingan batas Sub DAS Bungbuntu DAS Tarokam secara kuantitatif ditunjukkan pada nilai luasan dari data BPDAS sebesar $48,13 \mathrm{~km}^{2}$ dan ASTER GDEM 48,20 km². Keliling data BPDAS sebesar 41,41 km dan ASTER GDEM 45,10 km. Nisbah kebulatan data BPDAS sebesar 0,353 dan ASTER GDEM 0,298.

\section{Saran}

1. Untuk penelitian lebih lanjut dapat dilakukan penelitian tentang penentuan jaringan sungai dari data $D E M$ dengan data yang lebih bervariasi. Salah satu rekomendasi ialah dari data Lidar yang memiliki ketelitian lebih baik.

2. Pembuatan batas Sub DAS Bungbuntu DAS Tarokam merupakan bagian SubDAS hulu dengan tingkat kemiringan 8-15\%, pada penelitian selanjutnya dapat diteliti pada Sub DAS bagian Hilir untuk menguatkan penelitian ini, atau dapat dilakukan pada Sub DAS bagian hulu pula dengan tingkat kemiringan yang lebih tinggi. 


\section{DAFTAR PUSTAKA}

Rahayu, S., Widodo, R.H., Noordwijk, M.V., Suryadi, I., \& Verbist, B., 2009. Monitoring Air di Daerah Aliran Sungai. World Argoforestry Center.

Soewarno, 1991. Hidrologi: Pengukuran dan Pengolahan Data Aliran Sungai (Hidrometri). Nova Bandung.

Menteri Kehutanan Republik Indonesia., 2013. Tata Cara Penetapan Batas DAS. Peraturan Menteri Kehutanan Republik Indonesia No: p59/Menhut-II. ., METI and NASA Release Version 2 ASTER Global DEM. U.S. Geological Survey / NASA LP DAAC.[Internet].<URL:https://lpdaac.usgs.gov/abo ut/news_archive/meti_and_NASA_release_versio n_2_aster_global_DEM $>$. Diakses tanggal 18 Maret 2014, pukul 13.09 BBWI. 